American Journal of Environmental Sciences 3 (4): 188-192, 2007

ISSN 1553-345X

(C) 2007 Science Publications

\title{
Analysis of Cross and Single Sided Naturally Ventilated Rooms Using CFD
}

\author{
K. Visagavel and PSS. Srinivasan \\ Department of Mechatronics and Mechanical Engineering, K.S.Rangasamy College of \\ Technology, Tiruchengode, Tamilnadu, India
}

\begin{abstract}
Natural ventilation contributes to the improvement of thermal comfort and quality conditions of the internal air, while at the same time it is recognized as a very efficient technique that, when applied properly. The present project refers to the numerical prediction of air velocities in cross and single-sided naturally ventilated rooms, which are considered along with atmospheric zone. Continuity and Momentum equations have been solved by Control Volume Method. SIMPLE and SIMPLEC algorithm are used to solve these equations. Steady, k- $\varepsilon$ turbulence model and incompressible flow of a constant property fluid under Boussinesq's approximation have been considered. The results are presented for both cross and single-sided naturally ventilated rooms by using Grid independence test.
\end{abstract}

Key words: Single-sided naturally ventilated rooms, k- $\varepsilon$ turbulence model, grid independence test, air velocity

\section{INTRODUCTION}

The ventilation of internal spaces, that is the refreshment of closed spaces, constitutes unquestionably one of the fundamental requirements for the achievement of appropriate conditions of healthy and thermally comfortable buildings, without creating significant wind currents that may disturb or create noise. The term 'ventilation' includes all thermal procedures where air in the interior of closed space is replaced by external air masses, entering through building openings. The natural ventilation contributes to the improvement of thermal comfort and quality condition of the internal air, while at the same time it is recognized as a very efficient technique that, when applied properly, leads to significant reduction of energy consumption for the cooling of buildings.

Effective ventilation is important for various buildings, including houses, shelters, mobile homes, warehouses, greenhouses, etc. There are two major natural ventilation types namely: cross and single-sided ventilation. In both cases, air is driven in/out of the building due to pressure differences across the openings, which result from the combined action of wind and buoyancy driven forces. The physical processes involved in both cases are very complex and the interpretation of their role in ventilation effectiveness is a difficult task. Single sided ventilation occurs when the building communicates with the outdoor environment through one or more openings located on the same exterior wall. Mathematical interpolation of the physical phenomena related to this type of ventilation has so far been handled by empirical and simulation models.

Sinha et al.., ${ }^{[1-3]}$ have numerically analyzed the room air distribution with or without buoyancy effects for different inlet or outlet configuration for cross ventilated rooms. Telbany et al., ${ }^{[4]}$ and Dascalaki et al., ${ }^{[5]}$ have experimentally investigated the natural ventilation in single-sided ventilation. Etheridge ${ }^{[6]}$ has presented non-dimensional graphs for natural ventilation design of both single sided and cross ventilated rooms. Dehghan et al., ${ }^{[7]}$ and Papakonstantinou et al. ${ }^{[8]}$ have focused on the analysis of ventilation aspects of single sided rooms using CFD. Ziskind et al. ${ }^{[9]}$ analyzed natural ventilation using solar heated roof experimentally. Eftekhari et al. ${ }^{[10]}$ have done both experimental and CFD simulation of air flow distribution in and around single-sided naturally ventilated rooms.

Ventilation analysis is carried out either for singlesided ventilated or for cross-ventilated rooms. Majority of research have concentrated on flow inside the room based on the calculated boundary conditions. The present investigation analyzes the ventilation aspects of both single-sided ventilated and cross ventilated rooms including the external air flow using CFD in order to make comparisons.

Corresponding Author: $\quad$ K. Visagavel Department of Mechatronics and Mechanical Engineering, K.S.Rangasamy College of Technology,Tiruchengode,Tamilnadu,India 
Problem investigated: Ventilation aspects of cross ventilated and single-sided ventilated rooms are investigated. Figure 1 shows the computational domain (two dimensional, 2D). The room is of width (L1) and height (H1). The room has an opening of height (W) at height of (H3) from the floor. The air flow over the building is represented by extending the computed domain in the front (L2), back (L3) and top (H2) sides as shown. In case of cross ventilated room the openings of same height $(\mathrm{W})$ are located on both the vertical (building) walls. The problem is investigated numerically using finite volume technique.

Solution methodology: The major assumptions involved in the investigations are as follows:

* The analysis is two-dimensional Cartesian coordinate system and steady state condition.

* The material properties are constant and flow is isothermal.

* The flow is turbulent

* Flow is incompressible and Newtonian.

Under the assumptions, the governing equations to be solved are as follows:

i) Continuity

$\frac{\partial u}{\partial x}+\frac{\partial v}{\partial y}=0$

ii) Momentum

$u \frac{\partial u}{\partial x}+v \frac{\partial u}{\partial y}=-\frac{1}{\rho} \frac{\partial p}{\partial x}+v\left(\frac{\partial^{2} u}{\partial x^{2}}+\frac{\partial^{2} u}{\partial y^{2}}\right)$

$u \frac{\partial v}{\partial x}+v \frac{\partial v}{\partial y}=-\frac{1}{\rho} \frac{\partial p}{\partial y}+v\left(\frac{\partial^{2} v}{\partial x^{2}}+\frac{\partial^{2} v}{\partial y^{2}}\right)$

Where $\rho$ is the density, $u$ is the velocity in $x$ direction, $\mathrm{v}$ is the velocity in $\mathrm{y}$-direction, $\mathrm{p}$ is the pressure and $\gamma$ is the kinematic viscosity. For modeling the turbulent quantity, standard two-equation k- $\mathrm{C}$ model is used.

The boundary conditions to solve the problem are: The air flow is given as Left Surface (LS) boundary condition $\left(\mathrm{u}_{\mathrm{i}}, \mathrm{v}_{\mathrm{i}}\right)$, the symmetry boundary condition is applied on the North Surface (NS), No slip boundary condition $(\mathrm{u}=0, \mathrm{v}=0)$ is applied on the floor (South Surface, SS) and the Building Surface (BS), Zero pressure boundary condition $(\mathrm{p}=0)$ is applied on the Right Surface (RS).

The two dimensional model is created using the GAMBIT software. Boundary layer type mesh is applied on the floor (SS) and Building Surfaces (BS). The uniform or expanding grid spacing is applied over the remaining regions. LS specified as velocity inlet, NS is specified as symmetry, SS and BS as wall and RS as pressure outlet boundary types. The entire region is treated as fluid (air) continuum.

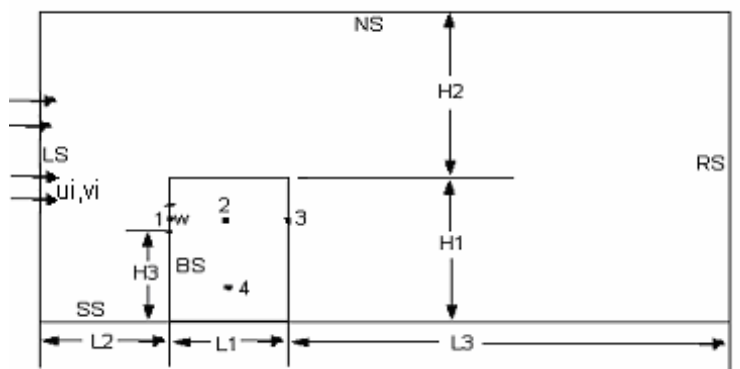

Fig. 1: Computational domain

The basic conservation equations are solved numerically using the FLUENT 6.0 CFD software. Steady state solver is activated. Air as fluid is defined and the boussinesq's model is selected. Gravity is activated. In boundary condition, value for the inletvelocity magnitude has been given. Iterated still the solution is converged up to residue level of $10^{-6}$. From the 'surface' option iso-surface is created for interpreting the variables at the intermediate grid points. The grid display, contour of properties, velocity vector (for total velocity, X-velocity, Y-velocity) and stream function are viewed from the 'Display' option. The grid independence test is carried out by experimenting with various grid sizes and watching how the solution changes with respect to the changes in grid sizes. Finally a stage will come when changing the grid spacing will not affect the solution. Using this as standard grid spacing, analyses are done. The grid dependence results at four location (1-4) marked in Fig. 1 are listed in Table 1 . The room region divided with 20 nodes is selected for further analysis.

\begin{tabular}{llll}
\multicolumn{4}{l}{ Table 1: Result obtained from grid independence test } \\
$\begin{array}{llll}\text { Velocity } \\
\text { Grid point }\end{array}$ & \multicolumn{1}{l}{ Input velocity $5 \mathrm{~km} \mathrm{hr}^{-1}=1.388 \mathrm{~m} \mathrm{~s}^{-1}$} \\
\cline { 2 - 4 } 1 & 10 nodes & 20 nodes & 30 nodes \\
\hline 1 & $1.74 \mathrm{~m} \mathrm{~s}^{-1}$ & $1.72 \mathrm{~m} \mathrm{~s}^{-1}$ & $1.7 \mathrm{~m} \mathrm{~s}^{-1}$ \\
3 & $0.76 \mathrm{~m} \mathrm{~s}^{-1}$ & $0.755 \mathrm{~m} \mathrm{~s}^{-1}$ & $0.75 \mathrm{~m} \mathrm{~s}^{-1}$ \\
4 & $0.2 \mathrm{~m} \mathrm{~s}^{-1}$ & $0.22 \mathrm{~m} \mathrm{~s}^{-1}$ & $0.23 \mathrm{~m} \mathrm{~s}^{-1}$ \\
& $1.1 \mathrm{~m} \mathrm{~s}^{-1}$ & $1.2 \mathrm{~m} \mathrm{~s}^{-1}$ & $1.3 \mathrm{~m} \mathrm{~s}^{-1}$
\end{tabular}

\section{RESULTS AND DISCUSSION}

For presenting the results room with $\mathrm{L} 1=3 \mathrm{~m}$, $\mathrm{H} 1=3 \mathrm{~m}, \mathrm{H} 3=2.2 \mathrm{~m}$ and $\mathrm{W}=0.5 \mathrm{~m}$ are used. After preliminary trial runs $\mathrm{L} 2=2 * \mathrm{~L} 1, \quad \mathrm{~L} 3=5 * \mathrm{~L} 1$ and $\mathrm{H} 2=3 * \mathrm{H} 1$ are found to be sufficient in order to model the exterior airflow. Grid independency of the results is made and $28 \times 38$ control volumes for the room region and $180 \times 100$ control volumes for the entire zone is found to give grid independent results. The results presented above are for these grid spacing. 


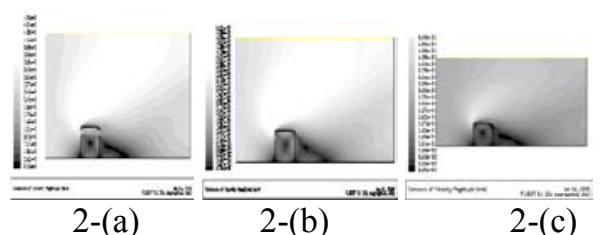

Fig. 2: Contour plot of Total Velocity for $\mathrm{u}_{\mathrm{i}}=0.277 \mathrm{~m} \mathrm{~s}^{-1}$ : (a) cross ventilated room;

(b) single-sided (windward) ventilated;

(c) Single sided (Lee ward) ventilation

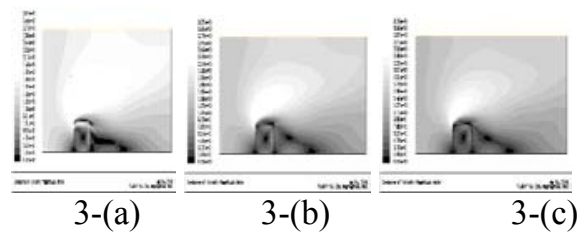

Fig. 3: Contour plot of Total Velocity for $\mathrm{u}_{\mathrm{i}}=1.388 \mathrm{~m} \mathrm{~s}^{-1}$.

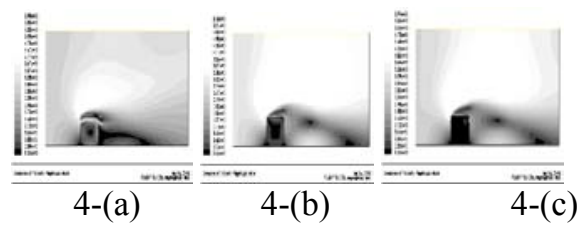

Fig. 4: Contour plot of Total Velocity for $\mathrm{u}_{\mathrm{i}}=2.777 \mathrm{~m} \mathrm{~s}^{-1}$

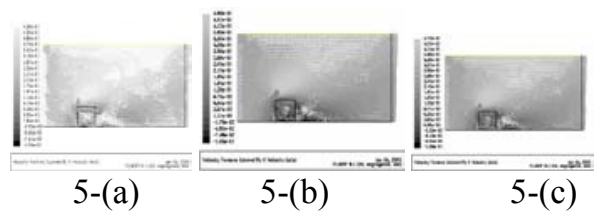

Fig. 5: Vector plot of $\mathrm{X}$ co-ordinate Velocity for $\mathrm{u}_{\mathrm{i}}=0.277 \mathrm{~m} \mathrm{~s}^{-1}$

(a) cross ventilated room;

(b) single-sided (windward) ventilated;

(c) Single sided (Lee ward) ventilation.

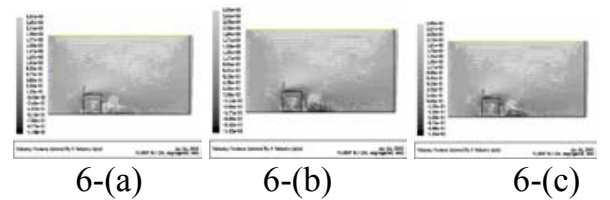

Fig. 6: Vector plot of $\mathrm{X}$ co-ordinate Velocity for $\mathrm{u}_{\mathrm{i}}=1.388 \mathrm{~m} \mathrm{~s}^{-1}$

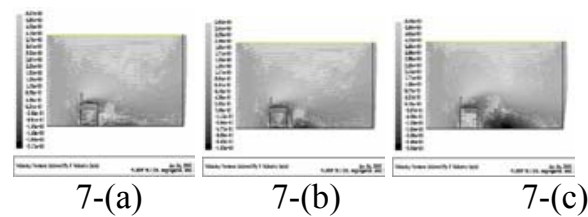

Fig. 7: Vector plot of $\mathrm{X}$ co-ordinate Velocity for $\mathrm{u}_{\mathrm{i}}=$ $2.777 \mathrm{~m} \mathrm{~s}^{-1}$

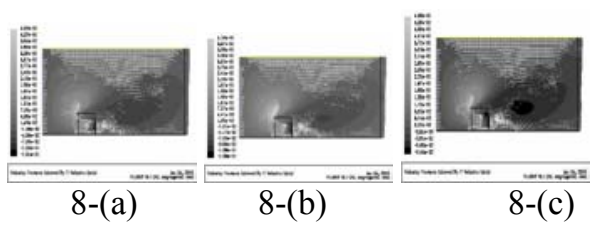

Fig. 8: Vector plot of $\mathrm{Y}$ co-ordinate Velocity for $\mathrm{u}_{\mathrm{i}}=$ $0.277 \mathrm{~m} \mathrm{~s}^{-1}$

(a) Cross ventilated room;

(b) single-sided (windward) ventilated;

(c) Single sided (Lee ward) ventilation.

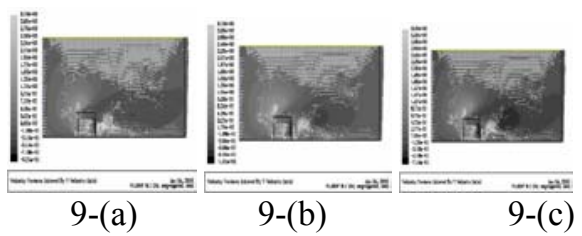

Fig. 9: Vector plot of Y co-ordinate Velocity for $\mathrm{u}_{\mathrm{i}}=$ $1.388 \mathrm{~m} \mathrm{~s}^{-1}$

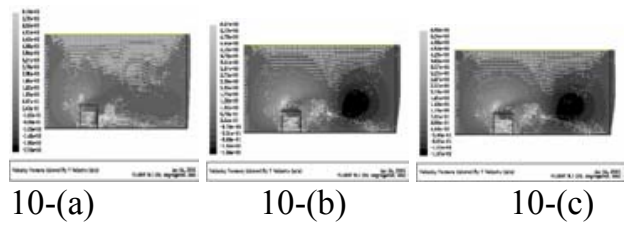

Fig. 10: Vector plot of $Y$ co-ordinate Velocity for $u_{i}$ $=2.777 \mathrm{~m} \mathrm{~s}^{-1}$

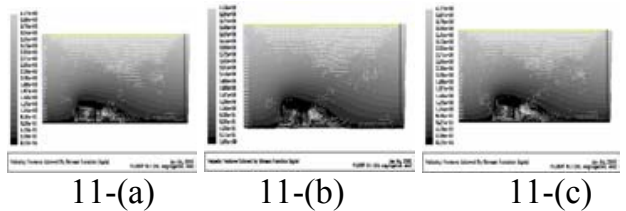

Fig. 11: Plot of Stream Function for $u_{i}=0.277 \mathrm{~m} \mathrm{~s}^{-1}$

(a) cross ventilated room;

(b) single-sided (windward) ventilated;

(c) Single sided (Lee ward) ventilation

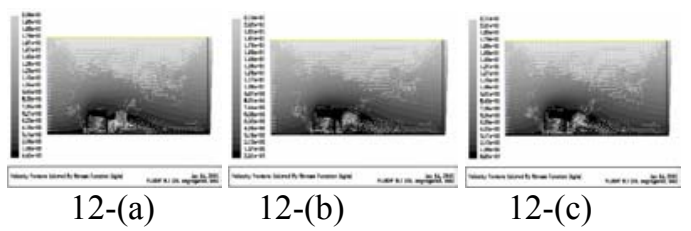

Fig. 12: Plot of stream function for $u_{i}=1.388 \mathrm{~m} \mathrm{~s}^{-1}$

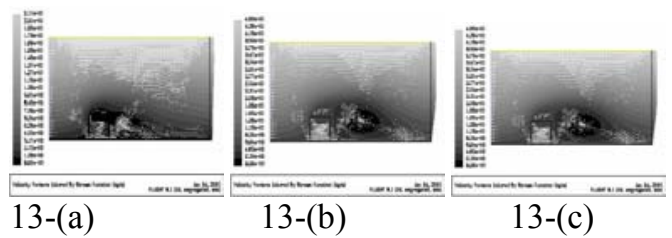

Fig. 13: Plot of stream function for $u_{i}=2.777 \mathrm{~m} \mathrm{~s}^{-1}$ 
Am. J. Environ. Sci., 3 (4): 188-192, 2007

Table 2: Velocity at four grid points locations for various cases

\begin{tabular}{|c|c|c|c|c|c|}
\hline Locations & x-co-ordinate $(\mathrm{m})$ & y-co-ordinate $(\mathrm{m})$ & $\begin{array}{l}\mathrm{V}_{\text {total }}\left(\mathrm{m} \mathrm{s}^{-1}\right) \\
\mathrm{u}_{\mathrm{i}}=0.277 \mathrm{~m} \mathrm{~s}^{-1}\end{array}$ & & \\
\hline & & & Case-1 & Case-2 & Case-3 \\
\hline 1 & 6 & 2.45 & 0.274 & 0.17 & 0 \\
\hline 2 & 7.5 & 2.45 & 0.014 & 0.01 & 0.01 \\
\hline 3 & 9 & 2.45 & 0.017 & 0 & 0.006 \\
\hline 4 & 7.5 & 1.22 & 0.0049 & 0.0046 & 0.0048 \\
\hline \multirow[t]{2}{*}{ Locations } & $\mathrm{x}$-co-ordinate $(\mathrm{m})$ & $\mathrm{y}$-co-ordinate $(\mathrm{m})$ & $\begin{array}{c}\mathrm{V}_{\text {total }}\left(\mathrm{m} \mathrm{s}^{-1}\right) \\
\mathrm{u}_{\mathrm{i}}=1.388 \mathrm{~m} \mathrm{~s}^{-1}\end{array}$ & & \\
\hline & & & Case-1 & Case-2 & Case-3 \\
\hline 1 & 6 & 2.45 & 1.7 & 1.1 & 0 \\
\hline 2 & 7.5 & 2.45 & 0.063 & 0.05 & 0.04 \\
\hline 3 & 9 & 2.45 & 1.1 & 0 & 0.014 \\
\hline 4 & 7.5 & 1.22 & 0.0235 & 0.024 & 0.025 \\
\hline \multirow[t]{2}{*}{ Locations } & $\mathrm{x}$-co-ordinate $(\mathrm{m})$ & $\mathrm{y}$-co-ordinate $(\mathrm{m})$ & $\begin{array}{c}\mathrm{V}_{\text {total }}\left(\mathrm{m} \mathrm{s}^{-1}\right) \\
\mathrm{u}_{\mathrm{i}}=2.777 \mathrm{~m} \mathrm{~s}^{-1}\end{array}$ & & \\
\hline & & & Case-1 & Case-2 & Case- 3 \\
\hline 1 & 6 & 2.45 & 3.5 & 2.03 & 0 \\
\hline 2 & 7.5 & 2.45 & 1.5 & 0.36 & 0.2 \\
\hline 3 & 9 & 2.45 & 2.5 & 0 & 1.2 \\
\hline 4 & 7.5 & 1.22 & 0.2 & 0.19 & 0.1 \\
\hline
\end{tabular}

Case-1: Cross ventilation in the room.

Case-2: Only left boundary surface of the room is open for ventilation.

Case-3: Only right boundary surface of the room is open for ventilation.

The wind velocities taken for analysis are $1 \mathrm{~km} \mathrm{hr}^{-1}$ $\left(\mathrm{u}_{\mathrm{i}}=0.277 \mathrm{~m} \mathrm{~s}^{-1}\right), 5 \mathrm{~km} \mathrm{hr}^{-1}\left(\mathrm{u}_{\mathrm{i}}=1.388 \mathrm{~m} \mathrm{~s}^{-1}\right)$ and $10 \mathrm{~km}$ $\mathrm{hr}^{-1}\left(\mathrm{u}_{\mathrm{i}}=2.777 \mathrm{~m} \mathrm{~s}^{-1}\right)$. The results obtained for the three wind velocities and three kind of ventilations (cross ventilation, single-sided (windward) ventilated and single-sided (Leeward) ventilated are presented in Fig. 2 to 13.The contour plots of total velocity are shown in Fig. 2 to 4 . The X-component velocity vectors are shown in Fig. 5 to 7 and that of Y-coordinate velocity in figure 8 to 10 . The stream function contours are shown in Fig. 11 to 13. Table-2 list the total velocity at four grid point locations (marked as 1, 2, 3 and 4 in Fig. 1). It can be observed that with the increase in wind velocity, the air velocity at four locations is found to increase, however not in the proportion. The location 4 represents the occupying zone.

\section{CONCLUSION}

This study draws attention to the physical procedures governing air movement during the natural ventilation through the description of a computational method. The work demonstrates that numerical solutions for ventilation problems can be obtained quickly and economically. Grid independence test is performed to get those solutions. In the specific case of the single-sided ventilated rooms, the results have been presented by considering atmosphere domain around the room. When the atmosphere air velocity increases the velocity in the room at different location increases by which recirculation zones are formed in the room. The value of air velocity is very less in the occupying zone for lower wind velocities $\left(1,5 \mathrm{~km} \mathrm{hr}^{-1}\right)$ and is significant only higher wind velocity $\left(10 \mathrm{kmhr}^{-1}\right)$ for all the three cases. It suggests that the inlet and outlet locations need to be suitably modified in order to get better comfort at low external wind flow rate.

\section{REFERENCES}

1. Sinha, S.L., R.C. Arora and Subhransu Roy, 2002. Numerical prediction of the laminar twodimensional room air flows with and without buoyancy. Fluid Mechanics and Fluid Power, pp: 563-568.

2. Sinha, S.L., R.C. Arora and Subhransu Roy, 2002. Numerical simulation of room air distribution with Buoyancy at different outlet locations. Fluid Mechanics and Fluid Power, pp: 181-190.

3. Sinha, S.L., R.C. Arora and Subhransu Roy, 2002. Numerical simulation of buoyant and non-buoyant flows in a room using a low-Reynolds number turbulence model. Fluid Mechanics and Fluid Power, pp: 569-575.

4. Telebany et al., 1985. Single sided ventilation PartI - The flow between a cavity and external air stream. Energy and Buildings, 20: 15-24.

5. Dascalaki et al., 1996. On the combination of air velocity and flow measurements in single sided natural ventilation configurations. Energy and Buildings, 24: 155-165. 
6. Etheridge, D.W., 2001. Non-dimensional methods for natural ventilation design. Building and Environments, 37: 1057-1072.

7. Mokhtarzadeh-dehghan et al., 1990. Transfer rates in single-sided Ventilation', Building and Environments, 25: 155-161.

8. Papakonstantinou et al., 2000. Numerically simulation of air flow field in single sided ventilated buildings. Energy and Buildings, 33: 4148.
9. Ziskind et al., 2001. Ventilation by natural convection of a one-story building. Energy and Buildings, 34: 91-102.

10. Eftekhari et al., 2003. Air flow distribution in and around a single sided naturally ventilation room. Building and Environments, 38: 389-397. 